\title{
EFFECT OF ONLINE HEMODIAFILTRATION ON PATIENTS WITH SEPSIS AND ACUTE KIDNEY INJURY IN INTENSIVE CARE UNIT
}

\author{
By \\ Mahmoud Mohammed Kasem Ibrahem , Mostafa Abd El-Fattah El- \\ Ballat, Nagah Mohamed Abo Mohamed, and Mohamed Ahmed El- \\ Sayed*
}

Departments of Internal Medicine and Clinical Pathology*, Faculty of Medicine, Al-Azhar University

Corresponding author: Mahmoud Mohammed Kasem Ibrahem,

E-mail: drmkasem2014@gmail.com

\begin{abstract}
Background: Acute kidney injury is a common occurrence in critically ill patients, with incidence rates of occurrence varying from 5 to $60 \%$ and a trend towards higher rates (30 to 60\%) when using the risk, injury, failure, loss of kidney function, end stage renal failure (RIFLE) or Acute Kidney Injury (AKI) Network (AKIN) classification.
\end{abstract}

Objective: To compare between effect of online hemodiafiltration and conventional hemodialysis in patients with sepsis and acute kidney injury in intensive care unit.

Patients and Methods: This study included forty (age and sex matched) patients with acute kidney injury (AKI) who were critically ill they were selected from the Nephrology Unit Ahmed Maher Teaching Hospital. The included patients were divided into two equal groups: Group (A) that included patients on online hemodiafiltration (OLHDF) and Group (B) that included patients on conventional hemodialysis.

Results: There was a statistically significant difference found between two groups after dialysis regarding $\mathrm{HB}$, WBCs, platelet, $\mathrm{Na}$ and albumin. Also, there was high statistically significant difference between two groups regarding urea, creat, $\mathrm{K}$ and PCT, and there was no statistically significant difference between the two groups regarding CRP.

Conclusion: OL-HDF showed to be better than IHD-LI in many aspects but there was no statistically significant difference in mortality.

Keywords: Online Hemodiafiltration, Acute Kidney Injury, Intensive Care Unit.

\section{INTRODUCTION}

Acute Kidney injury occurs in a variety of settings, and has clinical manifestations ranging from a minimal elevation in serum creatinine levels to anuric renal failure. In fact, AKI exists along a continuum of disease: the acute decline in kidney function is often secondary to an injury that causes functional or structural changes in the kidneys. As the severity of the underlying renal injury increases, the risk of unfavorable outcome rises (Zhang, 2015).

Sepsis is the body's response to infection. Sepsis is 'severe' when infection leads to organ dysfunction or failure. Septic shock is present when infection causes acute circulatory failure 
that leads to persistent hypotension despite adequate fluid resuscitation. The sepsis syndrome is no longer seen just as a disorder of uncontrolled inflammation; it is regarded more as a syndrome reflecting loss of balance between pro-inflammatory and anti-inflammatory mediators resulting in organ damage and development of the multiple organ dysfunction syndrome with its associated high mortality (Azkarate et al., 2015).

Sepsis syndrome can occur with or without acute kidney injury (AKI; formerly known as acute renal failure (ARF)). Renal replacement therapy (RRT) is necessary in about $6 \%$ of critically ill patients, according to a large multinational, multicenter survey, and it is provided as supportive treatment to AKI patients, preventing additional disorders (hypervolemia, metabolic acidosis, progressive uremia, and hyperkalemia) (Azkarate et al., 2015).

Online hemodiafiltration (OL-HDF) is a mixed technique that combines a standard hemodialysis diffusive transport with a significant amount of convective transport, thus provides a greater clearance of medium and large molecularsize, which is difficult to remove by diffusion alone. This technique requires a biocompatible high flux and permeability membranes, as well as precise machines with ultrafiltration control and ultrapure dialysate fluid for replacement. There is a high economic impact in OL $-\mathrm{HDF}$ implementation, so it is necessary to know the real benefits for applying (Darío et al., 2017).

In Egypt, continuous renal replacement therapy (CRRT) is not widely available, so that patients are treated with SLED,
IHD-LI or IHD-HI or intermittent OL$\mathrm{HDF}$ and there are no comparative studies about benefits between the procedures so this study is developed in order to consolidate and choose the best procedure adapted to developing countries.

The aim of this study was to compare between effect of online hemodiafiltration and conventional hemodialysis in patients with sepsis and acute kidney injury in intensive care unit.

\section{PATIENTS AND METHODS}

This prospective study that was conducted on forty patients with age and sex matched with Acute Kidney Injury (AKI) and critically ill at ICU and Nephrology Units, Ahmed Maher Teaching Hospital, after taking the approval of the ethical committee of internal medicine department. Informed consent was taken from all patients included in the study.

Patients into 2 equal groups: Group (A) included patients with AKI on online hemodiafiltration (OLHDF), their ages ranged between 26 and 58 years with a mean of $44.85 \pm 7.89$ years. 14 of them were males and 6 were females. They received OL-HDF with mixed replacement (pre and post dilutional) therapy. Group (B) included patients with AKI on conventional hemodialysis, their ages ranged between 29 and 58 years with a mean of $44.15 \pm 7.70$ years. 13 of them were males and 7 were females.

Inclusion criteria: Patients aging 16 years or more, patients presenting with a critical illness who developed acute kidney injury either at presentation or after admission and AKI as defined according to the AKIN criteria (AKIN-III). 
Exclusion criteria: Age $<16$ years, patients with chronic kidney disease including ESRD who are on renal replacement therapy (RRT) and patients who have malignant diseases.

All patients were subjected to the following: Full history taking from patients if possible or from relatives. Complete clinical examination. Basal laboratory work-up:(serum creatinine, Blood Urea, URR, S. Na, S. K, S. Albumin, Complete Blood Picture, C. Reactive protein S. Procalcitonin, Blood culture and sentivity test When indicated). Dialysis related clinical complications especially: Intradialytic Hypotension and arrhythmias. Mortality Rate of patients in this study. Intensive Care Unit (ICU) Stay of patients. Acute Physiology and Chronic Health Evaluation Score (APACHE II Score) The Quick sequential organ failure assessment score (qSOFA score).

Test for PCT (BRAHMS PCT-Q) was using immunochromatographic technique. A colored band appeared 30 minutes after application of $200 \mu \mathrm{L}$ serum or plasma with the intensity of the band read against a reference card. The results were reported as < $0.5,0.5-2.0,2.0-10$ and $>10 \mu \mathrm{g} / \mathrm{L}$.

For serum samples, blood was collect in a tube without anticoagulant and was allowed to clot. Serum was separated from blood as soon as possible to avoid hemolysis. Only clear, non-hemolyzed specimens were used. Testing was performed immediately after the specimens have been collected. The blood was stored at $2^{\circ} \mathrm{C}$ to $8^{\circ} \mathrm{C}$ for up to three days if the tests cannot be performed immediately.

Ethics and patient consent: All procedures followed Al-Azhar University ethical committee regulations, and written consents were taken from patients or relatives.

Financial support: No financial support.

\section{Statistical Analysis:}

All data were subjected to revision and validation then description and analysis on IBM-compatible PC by using SPSS (Statistical Package for the Social Sciences) program version 22.0.0, Microsoft Office Excel 2007, and Graph Pad Prism 6. Descriptive statistics were performed for all studied parameters in the three studied groups and were presented in the form of mean, median, standard deviation (SD), range, and percentages. Analytical comparison between different groups was done by using student t test, Mean-Whitney U test. Chi-square test was used to component numbers. $\mathrm{P}$ value < 0.05 was considered significant.

\section{RESULTS}

The number of studied cases was 40 cases, including 28 males by $67.5 \%$ and 13 females by $32.5 \%$, with an average age of 44.50 and a standard deviation of 7.70, and the lowest age of patients was 26 years and the oldest was 58 years (Table 1). 
Table (1): Distribution of the studied cases according to age, sex, cause and blood culture

\begin{tabular}{|l|l|c|}
\hline \multirow{2}{*}{ Parameters } & \multicolumn{1}{r|}{ All Cases } & No.= 40 \\
\hline \multirow{2}{*}{ Age (years) } & Mean \pm SD & $44.50 \pm 7.70$ \\
\cline { 2 - 3 } & Range & $26-58$ \\
\hline \multirow{2}{*}{ Sex } & Female & $13(32.5 \%)$ \\
\cline { 2 - 3 } & Male & $27(67.5 \%)$ \\
\hline \multirow{3}{*}{ Cause of AKI } & Ischemic & $5(12.5 \%)$ \\
\cline { 2 - 3 } & Septic & $27(67.5 \%)$ \\
\cline { 2 - 3 } & Toxic & $8(20.0 \%)$ \\
\hline \multirow{3}{*}{ Blood Culture } & None detected & $29(72.5 \%)$ \\
& Gram Positive & $11(37.9 \%)$ \\
& Gram Negative & $18(62.1 \%)$ \\
\hline
\end{tabular}

There was no statistically significant difference found between two groups regarding $\mathrm{HB}, \mathrm{WBCs}$, platelet, urea, creat,
URR, Na, K, albumin, PCT and CRP (Table 2).

Table (2): Comparison between pre conventional hemodialysis group and pre online HDF group

\begin{tabular}{|c|c|c|c|c|}
\hline \multirow{2}{*}{\multicolumn{2}{|c|}{$\begin{array}{ll}\text { Parameters } & \text { Groups } \\
\end{array}$}} & \multirow{2}{*}{$\begin{array}{c}\begin{array}{c}\text { Conventional } \\
\text { hemodialysis }\end{array} \\
\text { No. }=20 \\
\end{array}$} & \multirow{2}{*}{$\begin{array}{c}\text { Online HDF } \\
\text { No. }=20\end{array}$} & \multirow{2}{*}{ P-value } \\
\hline & & & & \\
\hline \multirow{2}{*}{$\mathrm{HB}(\mathrm{gm} / \mathrm{dl})$} & Mean \pm SD & $10.22 \pm 1.63$ & $11.17 \pm 1.64$ & \multirow{2}{*}{0.074} \\
\hline & Range & $7.8-13.4$ & $9-15$ & \\
\hline \multirow{2}{*}{ WBCs $\left(10^{3}\right)$} & Mean \pm SD & $11.69 \pm 3.97$ & $13.81 \pm 3.36$ & \multirow{2}{*}{0.076} \\
\hline & Range & $5.2-17.8$ & $10.2-20$ & \\
\hline \multirow{2}{*}{ Platelets (/microliter) } & Mean \pm SD & $193.75 \pm 68.84$ & $235.60 \pm 105.35$ & \multirow{2}{*}{0.145} \\
\hline & Range & $122-358$ & $168-503$ & \\
\hline \multirow{2}{*}{ Urea (mg/dl) } & Mean \pm SD & $51.24 \pm 10.83$ & $53.64 \pm 17.80$ & \multirow{2}{*}{0.610} \\
\hline & Range & $32.5-67$ & $33-86.3$ & \\
\hline \multirow{2}{*}{ Creat (mg/dl) } & Mean \pm SD & $5.86 \pm 1.63$ & $6.71 \pm 1.30$ & \multirow{2}{*}{0.076} \\
\hline & Range & $2.7-9.7$ & $5.3-9$ & \\
\hline \multirow{2}{*}{ URR } & Mean \pm SD & $31.71 \pm 16.56$ & $38.35 \pm 11.49$ & \multirow{2}{*}{0.148} \\
\hline & Range & $7.07-53.65$ & $25.9-59.33$ & \\
\hline \multirow{2}{*}{$\mathrm{S} . \mathrm{Na}^{+}(\mathrm{mg} / \mathrm{dl})$} & Mean \pm SD & $137.80 \pm 1.62$ & $138.75 \pm 2.98$ & \multirow{2}{*}{0.218} \\
\hline & Range & $135-140.6$ & $135.1-145$ & \\
\hline \multirow{2}{*}{$\mathrm{S} . \mathrm{K}^{+}(\mathrm{mg} / \mathrm{dl})$} & Mean \pm SD & $7.42 \pm 1.29$ & $7.82 \pm 0.96$ & \multirow{2}{*}{0.266} \\
\hline & Range & $5-9.7$ & $6.4-9$ & \\
\hline \multirow{2}{*}{ S.Albumin $(\mathrm{g} / \mathrm{dl})$} & Mean \pm SD & $3.40 \pm 0.31$ & $3.67 \pm 0.56$ & \multirow{2}{*}{0.070} \\
\hline & Range & $3-3.9$ & $2.9-4.5$ & \\
\hline \multirow{2}{*}{$\mathrm{PCT}(\mathrm{ng} / \mathrm{ml})$} & Mean \pm SD & $0.53 \pm 0.22$ & $0.65 \pm 0.24$ & \multirow{2}{*}{0.095} \\
\hline & Range & $0.1-0.9$ & $0.2-1$ & \\
\hline \multirow{2}{*}{ CRP (mg/dl) } & Mean \pm SD & $9.57 \pm 5.71$ & $11.87 \pm 7.52$ & \multirow{2}{*}{0.284} \\
\hline & Range & $2-20$ & $2.3-25$ & \\
\hline
\end{tabular}


There was a statistically significant difference found between two groups regarding $\mathrm{HB}$, WBCs, platelet, $\mathrm{Na}$ and albumin, urea, creat, $\mathrm{K}$ and $\mathrm{PCT}$, and there was non-statistically significant difference found between two groups regarding CRP (Table 3).

Table (3): Comparison between post conventional hemodialysis group and post online HDF group

\begin{tabular}{|c|c|c|c|c|}
\hline \multirow{2}{*}{\multicolumn{2}{|c|}{$\begin{array}{ll}\text { Parameters } & \text { Groups } \\
\end{array}$}} & $\begin{array}{l}\text { Conventional } \\
\text { hemodialysis }\end{array}$ & $\begin{array}{c}\text { Online } \\
\text { hemodialysis }\end{array}$ & \multirow[t]{2}{*}{ P-value } \\
\hline & & No. $=20$ & $\begin{array}{c}\text { hemodialysis } \\
\text { No. }=\mathbf{2 0}\end{array}$ & \\
\hline \multirow{2}{*}{$\mathrm{HB}(\mathrm{g} / \mathrm{dl})$} & Mean \pm SD & $10.63 \pm 0.92$ & $11.45 \pm 1.29$ & \multirow{2}{*}{0.025} \\
\hline & Range & $9-11.7$ & $9-13.4$ & \\
\hline \multirow{2}{*}{ Wbcs $\left(10^{3}\right)$} & Mean \pm SD & $8.01 \pm 2.37$ & $9.45 \pm 1.93$ & \multirow{2}{*}{0.042} \\
\hline & Range & $4.2-12$ & $4.3-11$ & \\
\hline \multirow{2}{*}{ Platelet (/microliter) } & Mean \pm SD & $200.7 \pm 69.1$ & $245.60 \pm 78.42$ & \multirow{2}{*}{0.049} \\
\hline & Range & $132-424$ & $157-424$ & \\
\hline \multirow{2}{*}{ Urea (mg/dl) } & Mean \pm SD & $22.64 \pm 4.69$ & $42.29 \pm 12.43$ & \multirow{2}{*}{0.000} \\
\hline & Range & $15.9-32.5$ & $21-71$ & \\
\hline \multirow{2}{*}{ Creat. (mg/dl) } & Mean \pm SD & $6.22 \pm 1.41$ & $3.94 \pm 0.4$ & \multirow{2}{*}{0.000} \\
\hline & Range & $3.5-9.5$ & $3.5-4.7$ & \\
\hline \multirow{2}{*}{$\mathrm{Na}(\mathrm{mEq} / \mathrm{L})$} & Mean \pm SD & $139.54 \pm 4.37$ & $136.86 \pm 2.25$ & \multirow{2}{*}{0.019} \\
\hline & Range & $135-154$ & $132.5-141.1$ & \\
\hline \multirow{2}{*}{$\mathrm{K}(\mathrm{mEq} / \mathrm{L})$} & Mean \pm SD & $3.79 \pm 0.7$ & $5.28 \pm 0.82$ & \multirow{2}{*}{0.000} \\
\hline & Range & $3-5.5$ & $3.5-6.5$ & \\
\hline \multirow{2}{*}{ Albumin (g/dl) } & Mean \pm SD & $3.2 \pm 0.27$ & $3.42 \pm 0.3$ & \multirow{2}{*}{0.025} \\
\hline & Range & $3-3.9$ & $3-3.9$ & \\
\hline \multirow{2}{*}{ PCT (ng/ml) } & Mean \pm SD & $0.92 \pm 0.20$ & $0.38 \pm 0.16$ & \multirow{2}{*}{0.000} \\
\hline & Range & $0.5-1.3$ & $0.1-0.7$ & \\
\hline \multirow{2}{*}{ CRP (mg/dl) } & Mean \pm SD & $10.21 \pm 5.28$ & $13.07 \pm 7.24$ & \multirow{2}{*}{0.162} \\
\hline & Range & $2-20$ & $4-25$ & \\
\hline
\end{tabular}

There was a statistically significant difference found between two groups regarding intradialytic hypotension and intradialytic arrhythmia, and non- statistically significant difference for mortality, ICU stay APATCHE II Score and qSOFA Score (Table 4). 
Table (4): Comparison between Conventional hemodialysis group and online HDF group regarding intradialytic hypotension and intradialytic arrhythmia, mortality and ICU stay, APATCHE II Score and qSOFA Score

\begin{tabular}{|c|c|c|c|c|c|c|}
\hline \multirow{2}{*}{\multicolumn{2}{|c|}{ Parameters }} & \multicolumn{2}{|c|}{$\begin{array}{l}\text { Conventional } \\
\text { hemodialysis }\end{array}$} & \multicolumn{2}{|c|}{ Online HDF } & \multirow{2}{*}{$\begin{array}{c}\text { P- } \\
\text { value }\end{array}$} \\
\hline & & No. & $\%$ & No. & $\%$ & \\
\hline \multirow{2}{*}{ Intradialytic hypotension } & Negative & 5 & $25.0 \%$ & 12 & $60.0 \%$ & \multirow{2}{*}{0.025} \\
\hline & Positive & 15 & $75 \%$ & 8 & $40.0 \%$ & \\
\hline \multirow{2}{*}{ Intradialytic arrhythmia } & Negative & 4 & $20 \%$ & 11 & $55.0 \%$ & \multirow{2}{*}{0.022} \\
\hline & Positive & 16 & $80 \%$ & 9 & $45.0 \%$ & \\
\hline \multirow{2}{*}{ Mortality } & Negative & 9 & $45.0 \%$ & 11 & $55.0 \%$ & \multirow{2}{*}{0.527} \\
\hline & Positive & 11 & $55.0 \%$ & 9 & $45.0 \%$ & \\
\hline \multirow{2}{*}{ ICU stay } & Prolonged & 11 & $55.0 \%$ & 8 & $40.0 \%$ & \multirow{2}{*}{0.342} \\
\hline & Reduced & 9 & $45.0 \%$ & 12 & $60.0 \%$ & \\
\hline \multirow{2}{*}{ APATCHE II Score } & Mean \pm SD & \multicolumn{2}{|c|}{$30.55 \pm 4.09$} & \multicolumn{2}{|c|}{$29.89 \pm 3.3$} & \multirow{2}{*}{0.578} \\
\hline & Range & \multicolumn{2}{|c|}{$23.2-37.5$} & \multicolumn{2}{|c|}{$23.4-36.2$} & \\
\hline \multirow{2}{*}{ qSOFA Score } & Mean \pm SD & & .47 & \multirow{2}{*}{\multicolumn{2}{|c|}{$\frac{0.2 \pm 0.41}{0-1}$}} & \multirow{2}{*}{0.478} \\
\hline & Range & \multicolumn{2}{|c|}{$0-1$} & & & \\
\hline
\end{tabular}

There was a statistically significant negative correlation between PCT (pre)

and urea (pre), and between PCT (post) and creat (post) and CRP (post) (Table 5).

Table (5): Correlations between PCT Pre and Post with age, HB, WBCs, platelet, urea, creat, URR, Na, K, albumin, APATCHE II score, qSOFA score and CRP in online hemodialysis group

\begin{tabular}{|l|c|c|c|c|}
\multirow{2}{*}{ Garameters } & \multicolumn{2}{c|}{$\begin{array}{c}\text { Online hemodialysis } \\
\text { (Pre) }\end{array}$} & \multicolumn{2}{c|}{$\begin{array}{c}\text { Online hemodialysis } \\
\text { (POST) }\end{array}$} \\
\cline { 2 - 5 } & \multicolumn{2}{|c|}{ PCT } & \multicolumn{2}{c|}{ PCT } \\
\cline { 2 - 5 } & R & P-value & r & P-value \\
\hline Age & -0.330 & 0.156 & 0.035 & 0.884 \\
\hline HB & 0.295 & 0.206 & -0.402 & 0.079 \\
\hline Wbcs & 0.026 & 0.914 & -0.043 & 0.858 \\
\hline Platelet & -0.194 & 0.412 & -0.265 & 0.258 \\
\hline Urea & $\mathbf{- 0 . 5 6 2}$ & $\mathbf{0 . 0 1 0}$ & 0.248 & 0.291 \\
\hline Creat & 0.270 & 0.250 & $-\mathbf{0 . 4 6 7}$ & $\mathbf{0 . 0 3 8}$ \\
\hline URR & -0.171 & 0.472 & -0.011 & 0.963 \\
\hline Na & 0.012 & 0.960 & -0.086 & 0.718 \\
\hline K & -0.223 & 0.345 & -0.117 & 0.623 \\
\hline Albumin & -0.318 & 0.172 & -0.190 & 0.422 \\
\hline APATCHE II Score & 0.292 & 0.212 & -0.366 & 0.113 \\
\hline qSOFA Score & 0.000 & 1.000 & -0.243 & 0.303 \\
\hline CRP & 0.115 & 0.630 & $\mathbf{- 0 . 6 3 7}$ & $\mathbf{0 . 0 0 3}$ \\
\hline
\end{tabular}




\section{DISCUSSION}

Acute kidney injury (AKI) is one of the most important complications during hospitalization, especially in critically ill patients. Recent data demonstrated that certain biomarkers including proinflammatory cytokines are associated with high morbidity and mortality (Peerapornratana et al., 2019).

These biomarkers, most of which have middle molecular weight, and proteinbound uremic toxins are limitedly removed by diffusion mechanism in conventional hemodialysis (Eloot et al., 2016).

Hemodiafiltration (HDF), a new modality that combines convective clearance with diffusion, could effectively enhance removal of middle molecule and protein-bound solutes. Therefore, HDF is increasingly used in several AKI settings such as septic AKI, rhabdomyolysisassociated AKI, myeloma cast nephropathy, and contrast-induced AKI (Canaud et al., 2018).

Our study revealed no a statistically significant difference between the two groups regarding age, sex and blood culture. There was statistically significant difference found between two groups regarding intradialytic hypotension and intradialytic arrhythmia which comes in agree with Masakane et al. (2017) on comparing $\mathrm{HDF}$ and $\mathrm{HD}$, serum $B 2-\mathrm{m}$ and albumin levels changed and this may be explained.

This was in contrary to Jean et al. (2015) in his study who don not confirm any hemodynamic advantage of HDF. These findings are not consistent with results from studies by Schiffl et al. (2013) who concluded that better preservation of RRF by high efficiency hemodiafiltration is not associated with left ventricular hypertrophy and Locatelli et al. (2010) who concluded that compared with conventional HD, convective therapies (HDF and HF) reduce ISH in long-term dialysis patients. Additionally, the ESHOL study reported fewer hypotensive episodes in the HDF group (Maduell et al., 2013), especially when higher convective volumes were achieved, as reported by Mora-Bravo et al. (2012).

Similarly, Jean et al. (2015) found no difference in blood pressure for HDF in association with intracellular or extracellular volume changes during sessions which supports our results. These findings not consistent with results from postdilution HDF (Schiffl et al., 2013) and predilution HDF studies (Locatelli et al., 2010). Similarly, no difference in blood pressure was found for HDF in association with intracellular or extracellular volume changes during sessions (Kumar et al., 2013). The favorable impact of HDF on hemodynamic stability is hypothesized to be due to higher sodium mass transfer. The cause of lower dialysis hypotension is avoiding critical blood volume reductions and/or improving cardiovascular compensatory mechanisms.

Our study showed that there was no statistically significant difference between two groups regarding mortality and ICU stay and also no statistically significant difference was found between two groups regarding APATCHE II Score and qSOFA Score. The explanation of these results could be explained by the limited number of cases, insufficient follow-up time, or failure to obtain a suitable 
minimum convective volume, issues that should be explored in future studies.

Jimenez et al. (2017) showed that patients with RRT have high mortality $(49.2 \%)$, similar to those reported in other studies where it reaches up to $70 \%$ (Poukkanen et al., 2015).

Prevalence in males and severity at admission to ICU are comparable to that reported in similar studies by Kaukonen et al. (2014), Azkarate et al. (2015) and Rama et al. (2016).

Like our study, Jimenez et al. (2017) revealed the severity grade at admission to ICU (APACHE, SOFA score) that showed no statistically significant differences between groups.

As regard to the laboratory data, our study revealed that there was a statistically significant difference found between the two groups after dialysis regarding $\mathrm{HB}$, WBCs, platelet, $\mathrm{Na}$ and albumin. Also, there was a statistically significant difference between two groups regarding urea, creat, $\mathrm{K}$ and PCT, and there was no statistically significant difference found between the two groups regarding CRP.

Our study showed significant differences between HDF and conventional hemodialysis as regard albumin level. Online with this result, $O k$ et al. (2013) reported lower albumin levels in the low-efficiency HDF of their prospective study.

Movilli et al. (2011) reported the absence of an albumin level decrease during an HDF protocol. The lower serum albumin level observed during the HDF periods could be due to a dialysate albumin loss, as reported previously by Combarnous et al. (2010) who observed an albumin loss of $1000-6800 \mathrm{mg} / \mathrm{session}$. Ahrenholz et al. (2010) reported a total albumin loss of 300-7000 mg/session, depending on the type of dialyzer used.

In contract, Den Hoedt et al. (2014) reported no difference in the rate of change in albumin between the HDF and low-flux HD. As serum albumin decreased mainly in patients with lower convection volume, the relationship between the change in albumin levels and the HDF technique itself remains unclear.

Den Hoedt et al. (2014) found that highly permeable membranes may increase albumin loss and lead to harmful consequences. However, they could not estimate accurately the extent of albumin loss through highly permeable dialysis membranes. This may be the result of improved dietary intake and potential explanation involving the removal of plasma substances that inhibit appetite.

Regarding the small molecule clearance, Jean et al. (2015) did not find differences between periods similar to Movilli et al. (2011) who also reported no advantage of HDF for urea and creatinine clearance. By contrast, Movilli et al. (2011) reported an increase in dialysis dose when using HDF vs. conventional hemodialysis, but higher blood flow rates in the HDF arm may have biased the results.

Pedrini et al. (2019), in a large observational study, confirm better control of anemia during hemodiafiltration which also supports our study.

Besides the modalities of CRRT, the CRRT dose utilized for sepsis-induced AKI is still unestablished. Prescribed and delivered doses of CRRT in AKI vary 
widely. Two large, multicenter RCTs were conducted in critically ill patients with AKI to investigate the effects of RRT dose on survival benefit (Kullaya et al., 2018).

In another RCT trial by Premuzic et al. (2017), the randomized evaluation of normal versus augmented level (RENAL) of replacement therapy study of critically ill patients meeting the criteria for initiation RRT was included and randomly assigned to post-dilution CVVHDF with effluent rate of 40 or $25 \mathrm{~mL} / \mathrm{kg} / \mathrm{hr}$ with no statistically significant difference of 90day mortality between high- and low-dose RRT groups.

Although the higher doses of CRRT are expected to provide more effective inflammatory cytokine removal in sepsis, subgroup analysis of patients with sepsis or organ failure revealed no significant differences in the mortality between the high- and low-intensity (Kullaya et al., 2018).

Also, our study showed a statistically significant negative correlation between PCT and urea pre-dialysis and there was a statistically significant negative correlation between PCT and creatinine post-dialysis.

Regarding the study by Chun et al. (2019) correlation analyses showed a positive correlation between PCT and hsCRP, AKI and sepsis.

Nakamura et al. (2015) evaluated the performance of PCT levels in the diagnosis of sepsis in patients with and without renal failure, finding a negative correlation between the levels of PCT and renal function, and suggesting that the kidney could be one of the organs responsible for the elimination of PCT. However, this has not been confirmed by others. Although the molecular weight of PCT is $13,600 \mathrm{Da}$ and therefore, it is ultrafilterable, it doesn't appear to accumulate in renal failure (Herget et al., 2010 and Steinbach et al., 2010).

\section{CONCLUSION}

OL-HDF showed to be better than IHD-LI in many aspects but there was no statistically significant difference in mortality.

\section{REFERENCES}

1. Ahrenholz PG, Winkler RE, Michelsen A, Lang DA and Bowry SK. (2010): Dialysis membrane-dependent removal of middle molecules during hemodiafiltration: the beta2microglobulin/albumin relationship. Clin Nephrol., 62(1):21-8.

2. Azkarate I, Choperena $G$ and Salas E. (2015): Epidemiology and prognostic factors of severe sepsis / septic shock. Six years of evolution. Medicina Intensiva., 40: $18-25$.

3. Canaud B, Vienken J, Ash S and Ward RA. (2018): Hemodiafiltration to Address Unmet Medical Needs ESKD Patients. Clin J Am Soc Nephrol., 13(9):14351443.

4. Combarnous F, Tetta C, Cellier CC, Wratten ML, Custaud and De Catheu T. (2010): Albumin loss in on-line hemodiafiltration. Int $\mathbf{J}$ Artif Organs, 25(3):203-9.

5. Darío J, Manuel G and Ana A. (2017): Intermittent Hemodialysis Low Intensity vs. on Line HemodiafiltrationinCritically Ill Patients with Sepsis and Acute Kidney Injury. Choosing the Best Treatment in a Developing Country. J Nephrol Ther., 7: 299-304. 
6. Den Hoedt CH, Bots ML, Grooteman MP, van der Weerd NC, Mazairac AH and Penne EL. (2014): Online hemodiafiltration reduces systemic inflammation compared to low-flux hemodialysis. Kidney Int., 86(2):423-32.

7. Eloot S, Schneditz D and Cornelis T. (2016): Protein-Bound Uremic Toxin Profiling as a Tool to Optimize Hemodialysis. PLoS One, 11 (1): 147153.

8. Herget Rosenthal S, Marggraf G, Pietruck F, Hüsing J, Strupat $M$ and Philipp T. (2010): Procalcitonin for accurate detection of infection in haemodialysis. Nephrol Dial Transplant, 16(5):975-979.

9. Jean G, Hurot JM, Deleaval P, Mayor $B$ and Lorriaux C. (2015): Onlinehaemodiafiltration vs. conventional haemodialysis: a cross-over study. BMC Nephrol., 16:70-75.

10. Jimenez DM, Guanuna A, Aguilar M, Morales F, Jimenez A, Duenas M, Castillo R, Gonzalez G, Paredes E and Pazos F. (2017): Intermittent Hemodialysis Low Intensity vs. on Line Hemodiafiltration in Critically Ill Patients with Sepsis and Acute Kidney Injury. Choosing the Best Treatment in a Developing Country. Journal of Nephrology \& Therapeutics, 17: 7-14.

11. Kaukonen K, Bailey M, Suzuki S, Pilcher D and Bellomo R. (2014): Mortality related to severe sepsis and septic shock among critically ill patients in Australia and New Zealand. JAMA, 311: 1308-1316.

12. Kullaya T, Paweena $S$ and Somchai E. (2018): Hemodiafiltration in Acute Kidney Injury, Aspects in Continuous Renal Replacement Therapy. Annals of Intensive Care, 10: 32-38.
13. Kumar V, Abbas AK and Aster JC. (2015): Robbins and Cotran pathologic basis of disease (Ninth edition.). Pbl. Philadelphia, Elsievier, Pp. 1408.

14. Locatelli F, Altieri P, Andrulli S, Bolasco P, Sau $G$ and Pedrini LA. (2010): Hemofiltration and hemodiafiltration reduce intradialytic hypotension in ESRD. $\mathrm{J}$ Am Soc Nephrol., 21(10):1798-807.

15. Lombardi R, Rosa-Diez $G$ and Ferreiro A. (2014): AcuteKidney Injury in Latin America: A view on renal replacement therapyresources. Nephrol Dial Transplant., 29: 1369-1376.

16. Maduell F, Moreso $F$ and Mora-Macia J. (2015): Reanalysis of the ESHOL study: All-cause mortality considering competition and time-dependent risks for renal transplantation. Nefrologia., 36: 156-163.

17. Maduell F, Moreso F, Pons M, Ramos $\mathbf{R}$, Mora-Macia $\mathbf{J}$ and Carreras $\mathrm{J}$. (2013): High-efficiency postdilution online hemodiafiltration reduces all-cause mortality in hemodialysis patients. J Am Soc Nephrol., 24 (3): 487-97.

18. Masakane I, Kan $K$ and Hideki $K$. (2017): Evidence for the clinical advantages of predilution on-line hemodiafiltration. Scientific Aspects of Dialysis Therapy, 189: 17-23.

19. Mora-Bravo FG, De-La-Cruz G, Rivera S, Ramirez AM, Raimann JG and Perez-Grovas H. (2012): Association of intradialytic hypotension and convective volume in hemodiafiltration: results from a retrospective cohort study. BMC Nephrol., 13:106-111.

20. Movilli E, Camerini $C$, Gaggia $P$, Poiatti P, Pola A and Viola BF. (2011): Effect of post-dilutional on-line haemodiafiltration on serum calcium, 
phosphate and parathyroid hormone concentrations in uraemic patients. Nephrol Dial Transplant, 26(12):4032-7.

21. Nakamura Y, Murai A, Mizunuma M, Ohta D, Kawano $Y$ and Matsumoto $N$. (2015): Potential use of procalcitonin as biomarker for bacterial sepsis in patients with or without acute kidney injury. J Infect Chem other, 21(4):257-63.

22. Ok E, Asci G, Toz H, Ok ES, Kircelli F and Yilmaz M. (2013): Mortality and cardiovascular events in online haemodiafiltration (OL-HDF) compared with high-flux dialysis: results from the Turkish OL-HDF Study. Nephrol Dial Transplant, 28(1):192-202.

\section{Peerapornratana S, Manrique-} Caballero CL, Gómez $H$ and Kellum JA. (2019): Acute kidney injury from sepsis: current concepts, epidemiology, pathophysiology, prevention and treatment. Kidney Int., 96(5):1083-1099.

24. Poukkanen M, Vaara ST and Reinikainen M. (2015): Predicting oneyear mortality of critically ill patients with early acute kidney injury: data from the prospective multicenter FINNAKI study. Crit Care, 125: 19-24.

25. Premuzic V, Basic-Jukic N, Jelakovic B and Kes P. (2017): Differences in CVVH vs. CVVHDF in the management of sepsis-induced acute kidney injury in critically ill patients. Journal of Artificial Organs, 20:326-334.

26. Rama I, Llaudó I and Fontova P. (2016): Onlinehemodia-filtration improves inflammatory state in dialysis patients: Alongitudinal study. 2016. PLOS ONE, 11: 164-69.

27. Schiffl H, Lang SM and Fischer R. (2013): Effects of high efficiency postdilution on-line hemodiafiltration or conventional hemodialysis on residual renal function and left ventricular hypertrophy. Int Urol Nephrol., 45(5): 1389-96.

28. Steinbach G, Bölke E, Grünert A, Storck $M$ and Orth K. (2010): Procalcitonin in patients with acute and chronic renal insufficiency. Wien Klin Wochenschr., 116 (24):849-853.

29. Zhang Z. (2015): Biomarkers, diagnosis and management of sepsis-induced acute kidney injury: a narrative review. Heart Lung Vessel, 7:64-73. 
تأثثير الإستصفاء الدموي مع الفلترة في مرضى الإعتلال

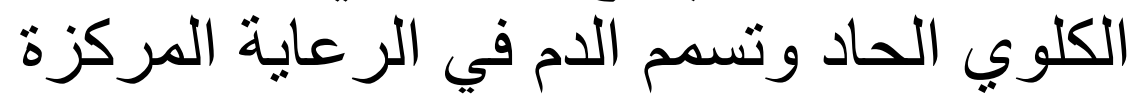

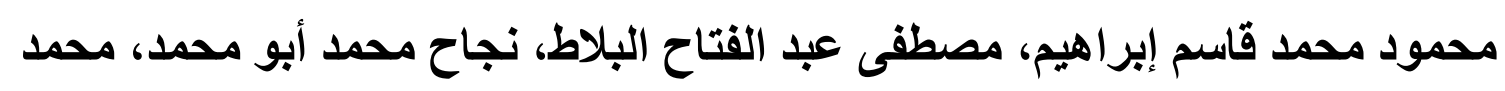

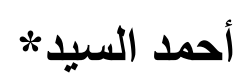

قسمي أمر اض الباطنة والكلى والباثولوجيا الإكلينيكية:، كلية الطب، جامعة الأزهر

E-mail: drmkasem2014@gmail.com

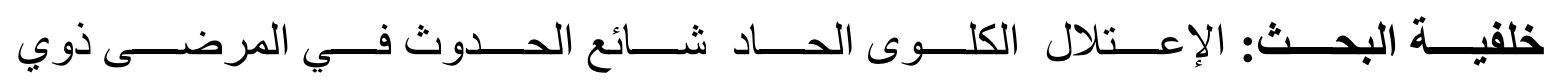

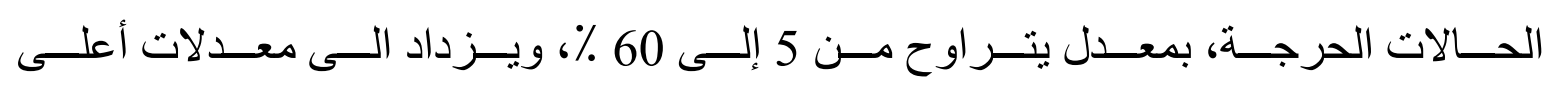

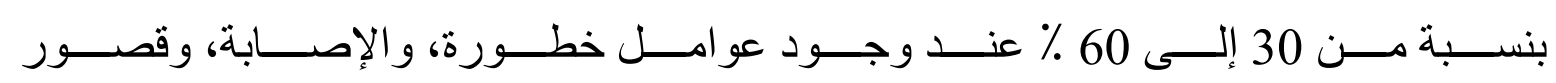
بوظائف الكلى، وصو لا إلى مرحلة الفشل الكلوي المزمن.

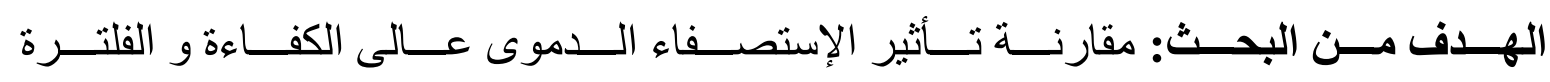

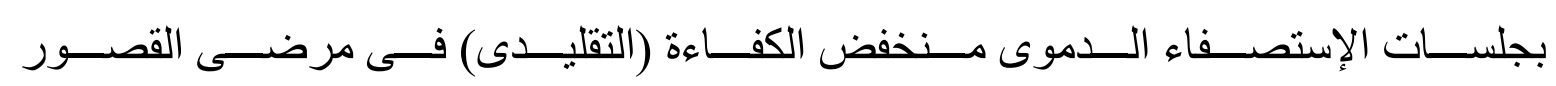

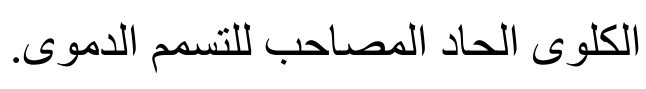

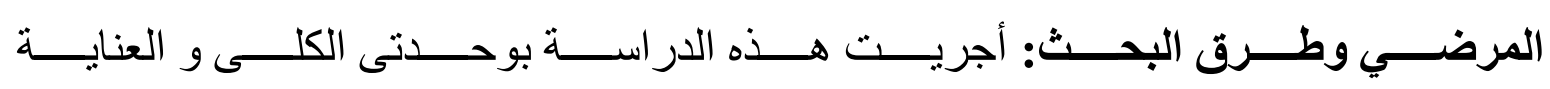

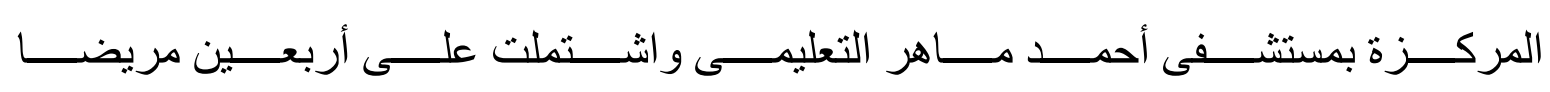

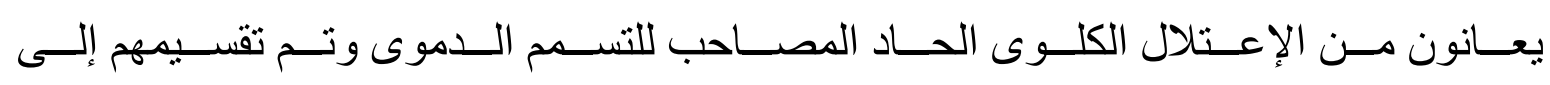

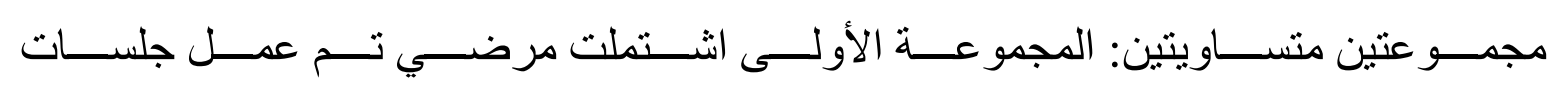

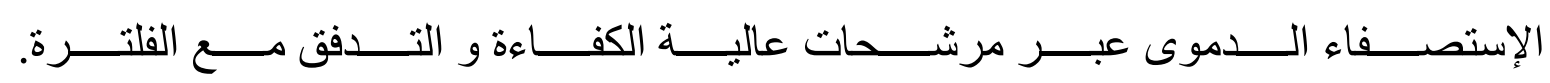

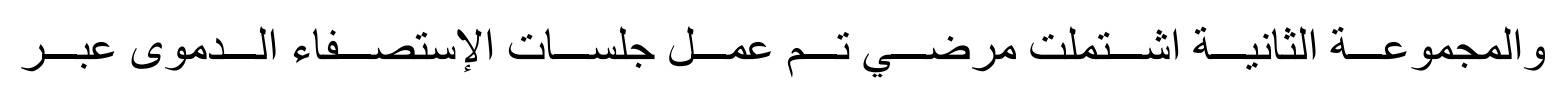
مرشحات منخفضة الكفاءة بدون تدفق (الغسيل الكلوى التقليدي).

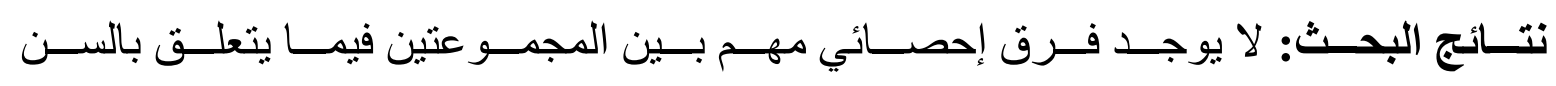

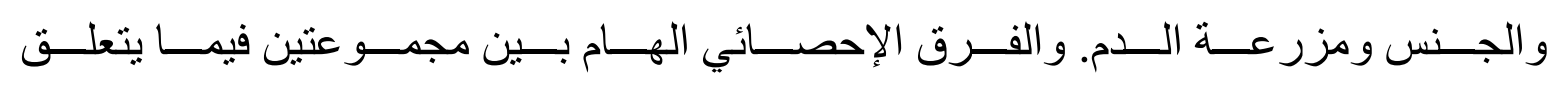

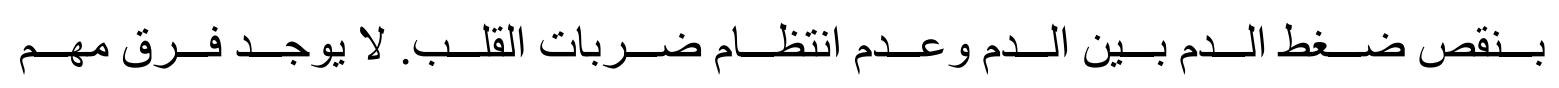

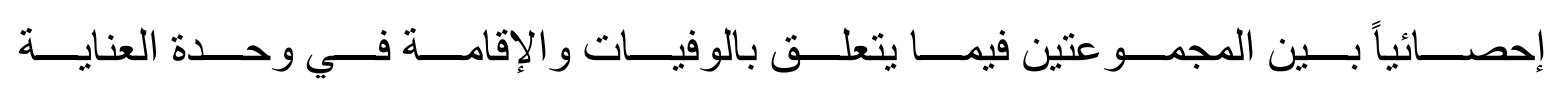

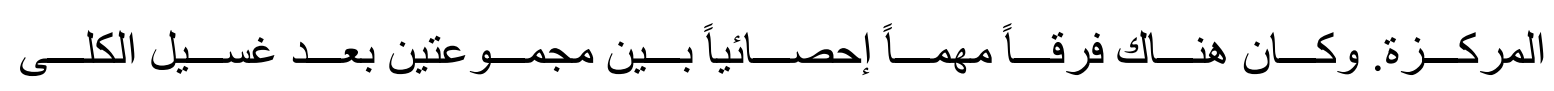




\section{EFFECT OF ONLINE HEMODIAFILTRATION ON PATIENTS WITH...}

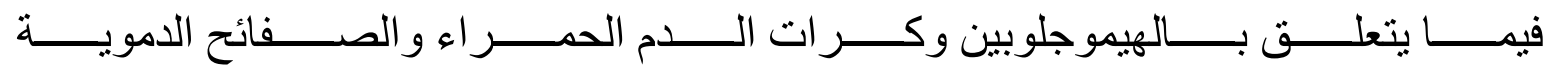

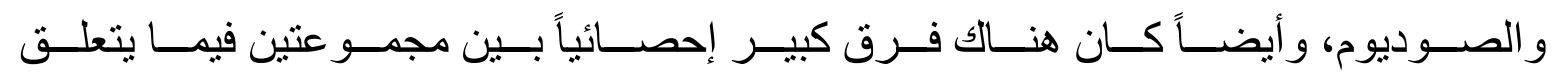
باليوريا و البوتاسيوم.

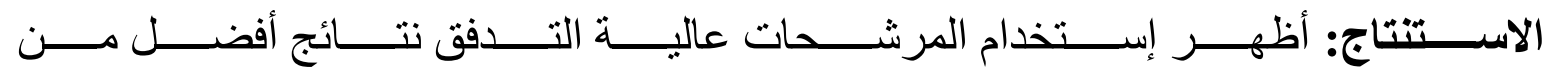

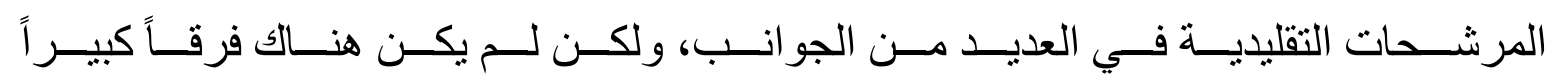

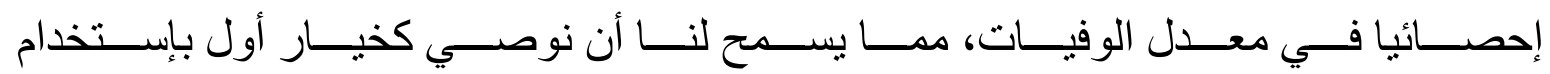

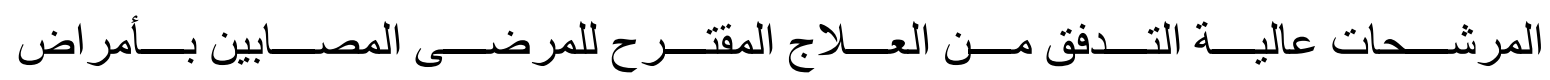
خطيرة مع إصابات الكلى الحادة.

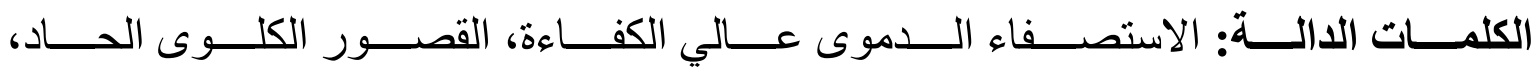
وحدة العناية المركزة. 